Goldschmidt 2021 Abstract

https://doi.org/10.7185/gold2021.6872

\section{Monogenetic Scoria Cones as Windows Into Transcrustal Mush}

NICHOLAS DEWITT BARBER ${ }^{1}$, SOPHIE BALDWIN ${ }^{2}$, MARIE EDMONDS ${ }^{1}$, HARYO EDI WIBOWO ${ }^{3}$ AND AGUNG HARIJOKO $^{3}$

${ }^{1}$ University of Cambridge

${ }^{2}$ University of Edinburgh

${ }^{3}$ Universitas Gadjah Mada

Presenting Author: ndb38@cam.ac.uk

Monogenetic volcanic fields (MVFs) are commonly associated with long-lived polygenetic composite volcanoes in many tectonic settings [1]. MVFs are compositionally diverse, but in many cases sample a primitive mafic composition that has been attributed to initial mantle melting [1-3]. The association between polygenetic and monogenetic volcanoes has raised questions as to the source of monogenetic melts - specifically, whether they are derived from the transcrustal mush feeding the main volcano [4], or from a different batch of parental magma [5]. To address this question, we studied a well-constrained suite of scoria samples from Gunung Slamet in Central Java, Indonesia, and its most distal monogenetic scoria cone, Gunung Loyang (Figure 1) [6]. Slamet is composed of calc-alkaline basalts [2,6], and has an extensive MVF on its eastern flank, similar to other Indonesian volcanoes $[5,6]$. We analyzed the textural and chemical features of the olivine cargo in both volcanoes, to test whether Loyang taps the broader transcrustal mush feeding Slamet. The olivines in both suites cluster in five textural groups, defined by the presence or lack of zoning and resorption, and according to the type and degree of zoning they exhibit. Olivines show a range of moderate to evolved Fo\% (Figure 2), and they also show significant variation in nickel contents (100-1400 ppm). Simple mass-balance models of the Ni drawdown in Slamet primitive melts indicate that the different textural and $\mathrm{Ni}$ signatures we observe can be explained by shallow vs. deep fractionation dominated by different mineral assemblages. Crucially, Loyang olivines seem to be drawn from the same petrological system as Slamet, but from a deeper amphibole-dominated part of the mush. Our work suggests that MVFs can be used as "petrological windows" into the deeper crustal levels of mush at active stratovolcanoes.

\section{References:}

[1] Németh, K. and Kereszturi, G. IJES; 104, 2131-2146. (2015)

[2] Reubi, O. et al. JVGR; 11, 1-4, 255-274. (2003)

[3] McGee, L.E. et al. JPet; 54, 10, 2125-2153. (2013).

[4] Coote, A. et al. Lithos; 344-345, 232-246. (2019).

[5] Carn, S. and Pyle, D. JPet; 42, 9, 1643-1683. (2001)

[6] Harijoko, A. et al. AIP; 1987, 020063-1-020063-9. (2018)
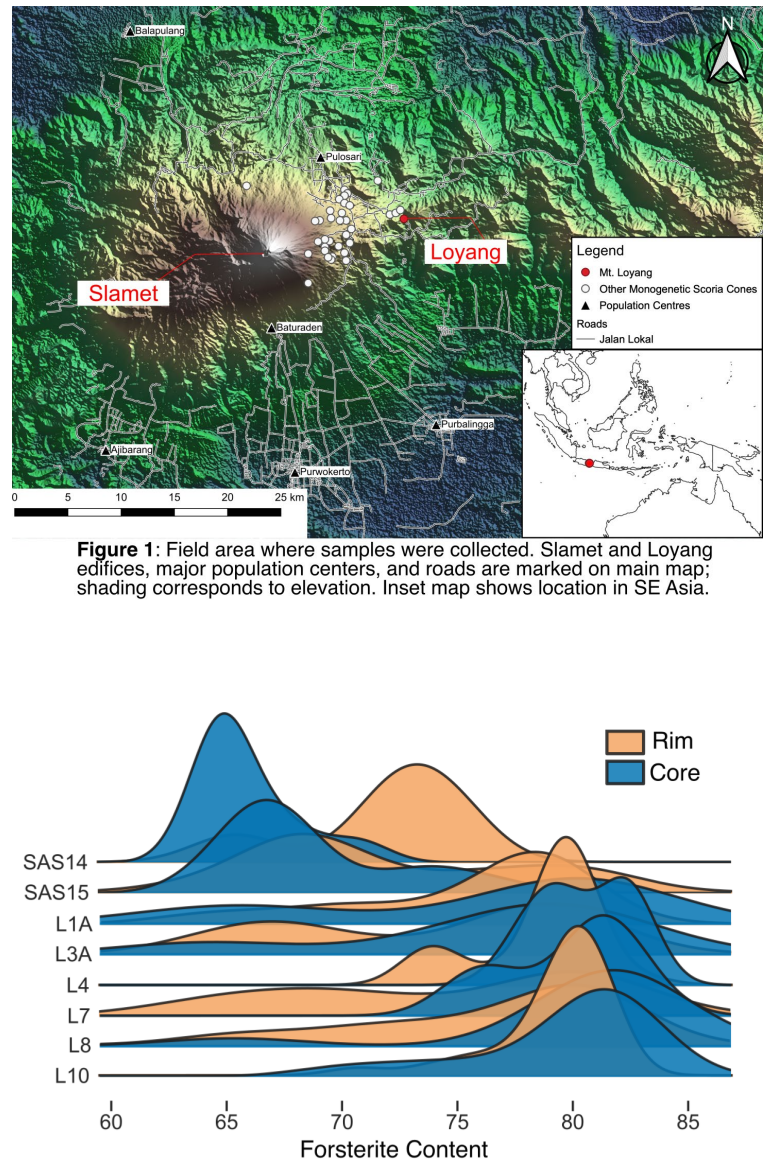

Figure 2: Distributions of Forsterite content (\%) in olivine cores (blue) $\mathrm{N}=351$. 